\title{
International Journal of Aquatic Research and Education
}

Volume 3 | Number 1

Article 1

2009

In This Issue ...

Stephen J. Langendorfer

Bowling Green State University, slangen@bgsu.edu

Follow this and additional works at: https://scholarworks.bgsu.edu/ijare

How does access to this work benefit you? Let us know!

\section{Recommended Citation}

Langendorfer, Stephen J. (2009) "In This Issue ...," International Journal of Aquatic Research and Education: Vol. 3: No. 1, Article 1.

DOI: https://doi.org/10.25035/ijare.03.01.01

Available at: https://scholarworks.bgsu.edu/ijare/vol3/iss1/1

This Editorial is brought to you for free and open access by the Journals at ScholarWorks@BGSU. It has been accepted for inclusion in International Journal of Aquatic Research and Education by an authorized editor of ScholarWorks@BGSU. 


\section{EDITORIALS}

International Journal of Aquatic Research and Education, 2009, 3, 1-3 (C) 2009 Human Kinetics, Inc.

\section{In This Issue . . .}

This issue marks the beginning of our third year for publication of the International Journal of Aquatic Research and Education. Having successfully published two complete volumes of peer-reviewed studies and having begun the third is particularly noteworthy because citation indices typically require at least two full years of publication prior to including any new serial among their references. As many potential authors will recognize, having one's work available in widely recognized citation indices is a critical requirement for adequate dissemination and recognition of one's work. The personnel committees who make critical tenure and promotion decisions at many institutions of higher education often rate journals according to a variety of criteria, including how they are indexed. So, I look forward to the eventual inclusion of the articles in the International Journal of Aquatic Research and Education in a variety of appropriate citation indices. I will keep readers informed of progress that IJARE makes relative to inclusion with indices.

As readers undoubtedly already will have discovered, this is the second issue in which we have featured an editorial written by a member of our IJARE Editorial Board. In this second instance, Bruce Becker, M.D., currently of Washington State University, has composed what I found to be a simply outstanding, thoroughly researched, and compellingly written editorial. He has chosen to address a continuing theme about the need for more and better research in the area of aquatics, specifically dealing with aquatic activity and exercise. Importantly, Bruce has not stopped at simply urging us all to produce more research. He has produced a terrific taxonomy of specific research needs organized around the very specific question of "What are the primary research needs in aquatic activity?" As you will note, his editorial provides detailed evidence about existing research, but more importantly, on the many unanswered aquatic activity questions that still need scrutiny and study. Thanks for this important contribution, Bruce. Readers, please pay close attention to Bruce's appeal for research. IJARE will particularly be interested in entertaining specific manuscript submissions for studies related to any or all of the important questions identified in Bruce's work.

This issue features four very solid research articles that I recommend for your reading and reference. Our lead article, coming to us from the University of Memphis and co-authored by Carol Irwin, Dick Irwin, Timothy Ryan, and Joris Ryan, "The Mythology of Swimming: Are Myths Impacting Minority Youth Participation?" is a USA Swimming-funded study that examines and debunks some commonly-held misconceptions about those who participate or don't participate in swimming instructional and competitive programs. I think this study will have major impact on refuting some traditional, but incorrect notions that surround the swimming field.

The second article, "Biophysiologic Effects of Warm Water Immersion," has been co-authored by Kasee Hildenbrand, Bruce Becker, Rebekah Whitcomb, and 
James Sanders of Washington State University. In their study, the authors examine some previously unexplored questions about how immersion and exercising in warm water affect human physiological systems, particularly the autonomic nervous system and physiologic measures mediated by the autonomic system.

Richard Hsiao from Indiana University of Pennsylvania has authored the third research tome in this issue, "An Analysis of Risk Management Implementation in Aquatic Centers in Taiwan and a Review of Selected Law Cases." Regular readers will recognize this study as a sequel to a previous publication in IJARE by Dr. Hsaio. I believe cross-cultural research, particularly that related to how different cultures view risk and legal issues, can be especially useful in promoting an understanding and appreciation of water safety issues.

The final research article, co-authored by Stathis Avramidis, David Llewellyn, and Ronald Butterly from the Leeds Metropolitan University, entitled "Drowning Incident Rescuer Characteristics: Encoding the First Component of the 4W Model," represents the authors' efforts at fleshing out a conceptual water safety model that they previously published in IJARE. Too often research studies are "single shot" efforts. What Stathis and his colleagues have undertaken is to have proposed a model and then systematically to have tested an element of that model. I anticipate future submissions as they pursue this admirable line of inquiry.

You will find two educational articles featured in this issue. The first article, "Aquatics Professional Development" comes to us as a joint work by Lee Yarger of Ball State University, and Bob Ogoreuc, of Slippery Rock University, both aquatic directors at their respective institutions. Lee and Bob share their experience-based insights into how we need to nurture future generations of aquatic professionals. It is an article well worth your perusal and consideration.

Stathis Avrimidis of Leeds Metropolitan University and the European Lifeguard Academy has contributed a second work for this issue in which he has reviewed issues related to lifeguard leadership. His professional article reflects his longstanding interest and work in the lifeguarding field. Regular readers will recognize Stathis from his many previous contributions to IJARE.

We complete this first issue of Volume 3 with two media reviews of recent Human Kinetics aquatic publications. The first review is of Susan Grosse's 2007 text, Water Learning. Susan's book represents a unique effort to help aquatic and other professionals appreciate how the water can serve as an important medium through which to promote a wide range of learning, in the cognitive, affective, and psychomotor domains. As you will learn from the review, it is not a "how-to-teach swimming" book, but something much more.

The second and final media review describes Emmett Hines' 2nd edition of his popular work, Fitness Swimming. Emmett, a Level 5 Masters swim coach, provides a revised text with a wide repertoire of information related to fitness, Masters, and open water swimming. Schooled in the Total Immersion method of teaching the front crawl stroke, he provides interested adult swimmers, instructors, and coaches with a wealth of useful drills and ideas for improving one's swimming efficiency, both through improved technique as well as conditioning. I personally learned a great deal in reviewing the text in preparation for composing the review.

Let me conclude by offering to others who may have or know of other aquatic texts, monographs, DVDs, or other media the opportunity to propose and/or write media reviews similar in nature to the ones in this and previous issues. To date, I 
have chosen to take the lead in writing these media reviews primarily focused on print publications from Human Kinetics. I do not intend to maintain a monopoly as author or in only focusing on HK publications. Please contact me if you have an aquatic-related work you would like to have reviewed or that you would like to review that may be of interest to our readership. Part of the IJARE mission is to provide information to the aquatic profession about a wide variety of aquatic information, regardless of its format, that may be available. The more the merrier!

Enjoy your reading!

Steve Langendorfer, Editor

International Journal of

Aquatic Research and Education 